\title{
LEVERAGING MULTI-GENERATIONAL WORKFORCE VALUES IN INTERACTIVE INFORMATION SOCIETIES
}

\author{
Authors: \\ Sophie van der Walt ${ }^{1}$ \\ Tanya du Plessis ${ }^{2}$
}

\section{Affiliations: \\ ${ }^{1}$ Centre for Information and Knowledge Management, \\ University of Johannesburg, South Africa}

${ }^{2}$ Department of Information and Knowledge Management, University of Johannesburg, South Africa

\section{Correspondence to:}

Tanya du Plessis

email:

tduplessis@uj.ac.za

\section{Postal address:}

Department of Information and Knowledge Management, University of Johannesburg, Kingsway Campus, PO Box 524, Auckland Park 2006,

South Africa

\section{Keywords:}

co-worker relationships; generational diversity; interactive information societies; multi-generational workforce; succession planning

\section{Dates:}

Received: 30 June 2010 Accepted: 28 Sept. 2010

Published: 19 Nov. 2010

How to cite this article: Van der Walt, S. \& Du Plessis, T., 2010, 'Leveraging multi-generational workforce values in interactive information societies', SA Journal of Information Management 12(1), Art. \#441, 7 pages. DOI: $10.4102 /$ sajim.v12i1.441

This article is available at: http:/ / www.sajim.co.za

Note:

This article is based on the Masters dissertation that was submitted to the Department of Information and Knowledge Management, University of Johannesburg in 2010. A competitive research article was presented at the Third Faculty of Management Conference, 12-14 May 2010, Johannesburg. This article significantly extends the conference article that was published in the conference proceedings.

\section{ABSTRACT}

Background: The success of organisations relies on various factors including the ability of its multigenerational workforce to collaborate within the interactive information society. By developing an awareness of the different values of a diverse workforce, organisations may benefit from diversity. Various diversity factors, such as ethnicity, age and gender, impact on the way people interact, especially in the interactive information society.

Objectives: This article advocates the need for generational awareness and addresses how this awareness presents benefits to companies, such as, increased productivity, improved succession planning policies and strategies to recruit and retain a diverse workforce. The research problem is directed at how diversity management influences Traditionalists, Baby Boomers, Generation X and Generation $\mathrm{Y}$ in terms of their work performance and co-worker relationships.

Method: The research design combines Critical Theory and Generational Theory within the mixedmethod paradigm. The sequential exploratory design was decided upon as it studies the unknown relationships between different generations of employees. The literature review was followed by a quantitative empirical research component and data was collected by means of a questionnaire. Results: The findings highlight specific differences between generations regarding their perspectives on work values and co-worker relationships, rewards, work-life balance and retirement.

Conclusion: The article concludes with recommendations on the role diversity management plays in terms of work performance and co-worker relationships. By leveraging generational awareness in the interactive information society organizations with a multi-generational workforce will succeed in the competitive business environment.

\section{INTRODUCTION}

The way we see the world is coloured by the experiences and influences we absorbed as children (Mannheim, 1952). Mannheim, a well-known sociologist, further explains how people of all ages act according to how they reacted to childhood experiences and assumptions as they entered their twenties. Now in their twenties and older, the current workforce perceives work and work performance differently. Many factors impact on the way people world-wide collaborate, interact and perform in the work environment. A condensed list of diversity factors includes culture, race, age, gender, socioeconomic status, literacy, physical ability and legacy.

As with other countries, South African co-worker relationships are sometimes negatively affected by diversity factors, specifically that of culture and race (Mabokela \& Mawila, 2004:4; Human 2005:34). However, identifying and leveraging diversity factors, such as age, diversity can present many advantages to organisations. Kagan (2003:1), Bell (2007:5) and Kreitz (2008:105) mention an increase in productivity, workforce cohesion, effective recruitment and volunteering programmes and improved leadership and succession planning policies as the main advantages of generational awareness and diversity management.

Besides its benefits, generational awareness also presents certain challenges to organisations. These findings could assist in raising the awareness of different generational cohorts' work values and what determines their sense of belonging, thereby aiding organisations in leveraging their multi-generational workforce values.

\section{RATIONALE AND RESEARCH PROBLEM STATEMENT}

The rationale for this study is found in the multi-generational character of interactive information societies and its effect on an increasingly ageing workforce, including international and national academic information professionals (Wilder 1996:385; Lancaster \& Stillman 2002; Sayers 2006; Hallam \& Lee 2008:15; Dwyer 2009). According to StatsSA (2007), 11.84\% of the South African population is estimated to be aged 50 years and over, necessitating succession planning and implementation during the next two decades.

Although a great deal of research has been conducted regarding diversity management in South Africa, very little of this research focused on age diversity within interactive information societies. From the literature review it was also observed that research was lacking in terms of work performance and coworker relationships. The study therefore aimed to address the following research problem: How does diversity management influence the different generations of co-workers working within the interactive information society in terms of their work performance and co-worker relationships? 
The research problem was directed specifically at how generations interact and perform their daily work not only to the benefit of the organisation, but also according to their unique generational preferences. The purpose of the study was to encourage organisations to take cognisance of the age demography of their current workforce and develop and implement not only succession planning policies, but also relevant recruitment and retention policies in order to avoid employee and leadership vacuums. This is in line with the research objectives:

- to identify the generations currently active in the South African interactive information society

- to explore the values of different generational cohorts with the aim to leverage these values in the workplace

- to draw the attention to the impact of age diversity on coworker relationships and investigate the role of generational awareness in a multi-generational workforce

- to collect, analyse and provide reliable data on the current age demography of academic information professionals

- to gain insight and benefit from generational diversity implications in terms of work performance, work-life balance, retirement, rewards, co-worker relationships and recruitment.

Given the above research objectives, the study is limited to information society research and does not include issues related to the subject fields of sociology, psychology or human resource management. Due to the research scope, the focus is on age diversity and excludes other diversity factors, such as race or gender. The empirical research does not consider all interactive information societies; rather it focuses on the academic information services (AIS) of higher education institutions (HEI) in South Africa.

The focus of the study is directed at how diversity management influences the different generations of information professionals working within the interactive information society specifically in terms of their work performance and co-worker relationships. In order to address the research problem a brief overview is required of, (1) interactive information societies and (2) the role played by diversity management in terms of work performance and co-worker relationships in academic information services. The brief overview is followed by the research findings with an analysis of the views of different generational groups on work performance and co-worker relationships. To begin with, interactive information societies are introduced to provide the necessary context to the study.

\section{INTERACTIVE INFORMATION SOCIETIES}

The 'interactive information society' is described as a place where individuals and communities can achieve their full potential and improve the quality of their lives through creating, accessing, using and sharing information and knowledge (WSIS 2005:9; Barnard 2008:13-14). What distinguishes interactive information societies from other information societies is what Surowiecki (2005) and Boothby (2006) describe as an allpervading, interactive 'connectedness'. Ferreira and Du Plessis (2009) explain that this connectedness refers to the inclination of individuals to seek constant access to information and other online services as well as their ability to connect with other individuals and groups through the use of technologies such as email, BlackBerries and various Social Web applications.

Individuals with this inclination are not necessarily bound to one generation; however each generation may have its preferences and choose to belong to certain interactive information societies. According to Arnold (2007:91), interactive information societies can be divided into two broad groups, (1) information content and commerce and (2) connectors and carriers, with various entities forming part of these two groups. Regardless of its interactive information society category, most organisations today employ diverse individuals who represent various generational cohorts.

\section{Generational cohorts in the labour market}

Determining how many generations are currently active in the labour market has proven to be a challenging exercise and the literature review indicates that researchers are not in agreement in this regard. Some argue that there are five generations in the workplace (Kennedy 2002; Novkovic 2007), others dispute this and argue for four (Codrington \& Grant-Marshall 2004; Howe \& Strauss 2007), whilst others reason that there are only three generations active in the workplace (Gursoy, Maier \& Chi 2007; Sayers 2007).

Although consensus on this matter seems problematic, most researchers do agree on the following generational cohorts, namely Traditionalists, Baby Boomers, Generation $X$ and Generation Y. But even naming these generations is problematic as each generation is attached to a myriad of labels. For example, Traditionalists are also labeled Pre-Boomers or the Silent Generation; Generation $X$ as Slackers or the MTV generation and Generation $\mathrm{Y}$ is referred to as NetGen, Millennials, GenD and Echo Boomers. In this study the cohorts are referred to as: Traditionalists, Baby Boomers, Generation X and Generation Y.

\section{Categorising each generation}

Another point upon which researchers differ is how to categorise each generation according to dates - here country of origin comes to the forefront. The United States of America seems to be in the lead in terms of birth dates; other countries, including South Africa, differ by as much as 15 years from the USA. The only true exception is Europe and the United Kingdom's lead in the Traditionalist cohort, categorising this generation as people born after 1917. Table 1 illustrates how different countries categorise generations according to date of birth (Gursoy et al. 2007; Sayers 2007; Kennedy 2002)

Table 1 also illustrates an important aspect of generations, namely that the boundaries separating these generations are not exact. It is important to note that the different generations overlap with each other. The fact that an individual could be from neither of the cohorts and instead form part of the so-called 'Cuspers', as labeled by sociologists, complicated the boundaries between each of the generations. Cuspers are individuals born either early in a generation, sharing some of the characteristics of the generation before, or late in a generation, sharing some of the characteristics of the following generation. An important advantage of Cuspers, especially in interactive information

TABLE 1

Categories of generations according to birthdates

\begin{tabular}{lllll}
\hline Generation & USA & Europe/UK & Australia & South Africa \\
\hline Traditionalists & $1923-1942$ & $1918-1945$ & $1922-1943$ & $1930-1949$ \\
& $1943-1945$ & & & \\
& $1925-1942$ & & &
\end{tabular}

$\begin{array}{lllll}\text { Baby Boomers } & 1943-1962 & 1946-1965 & 1943-1960 & 1950-1969\end{array}$

Generation X $\quad 1963-1983 \quad 1966-1984 \quad 1960-1980 \quad 1970-1989$

$1960-1978$

$1961-1980$

$\begin{array}{llll}\text { Generation } Y & 1984-2001 & 1985-2001 \quad 1980-2000 & 1990-2005 \\ & 1979-1984+ & & \\ & 1981-2000 & & \\ & 1982+\end{array}$

Sources: Gursoy, D., Maier, T.A. \& Chi, C.G., 2007, 'Generational differences: An examination of work. values and generational gaps in the hospitality workforce', International Journal of Hospitality Management 27(3), 448-458.

Kennedy, M.M., 2002, 'Managing change: Understanding the demographics of the evolving workforce', Proceedings of the Annual Convention of the AAEP 2002, 48, 467-470. Sayers, R.M., 2007, 'The right staff from $X$ to $Y$ : Generational change and professional development in future academic libraries', Library Management 28(8/9), 474-487. 


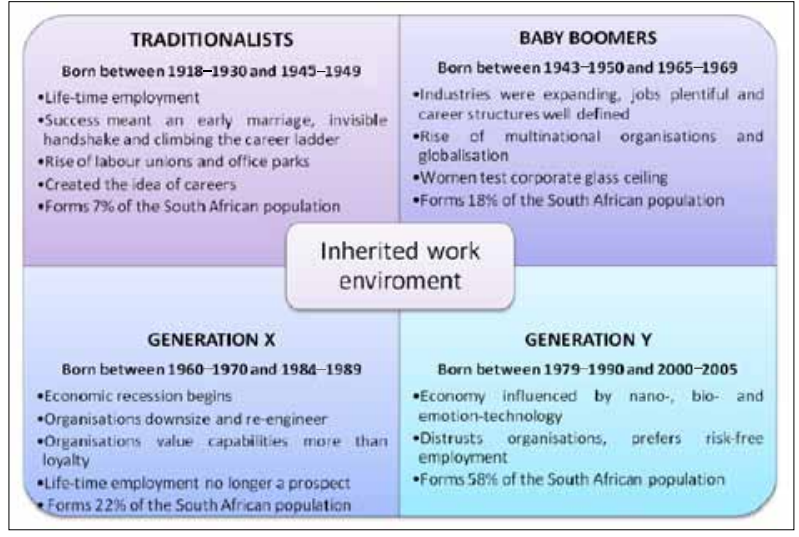

FIGURE 1

Inherited work environment of each generation

societies, is their ability to perceive both sides of a generational issue, identifying not only with the generation before but also the generation after. Perspectives on Cuspers and the four other cohorts' values and preferences are discussed in more detail in Van der Walt (2010:66-129). Here it suffices to conclude that there are different generational cohorts currently active in the workplace which requires an understanding of the role diversity management plays and specifically, age diversity.

\section{AGE DIVERSITY, WORK PERFORMANCE AND CO-WORKER RELATIONSHIPS}

It is important to understand the role age diversity plays in the interaction between co-workers in the interactive information society and how this interaction influences their work performance. However, Kennedy (2002:467), Bogaert and Vloeberghs (2005) and Bell (2007:4) warn that although it is imperative for organisations to develop and execute diversity policies, focusing on every individual's diversity will make the concept futile. Instead generational diversity should be acknowledged and understood. This implies knowing employees' age profiles, understanding their generational cohorts and how they interact, what their shared values are and its effect on work productivity. Figure 1 illustrates the four generations together with a summary of their inherited work environment. The inherited work environment provides the conditions for an understanding of the different generations' perspectives on work performance.

In Figure 1 the categorisation of the birth ranges per cohort are interpreted as follows: 'the earliest year born into a generation (global) or earliest year born into a generation (South Africa)' to 'latest year born into a generation (global) or latest year born into a generation (South Africa)'. Having a clear perception of these categories of employees can be used to the organisation's advantage.

\section{Benefits of diversity}

Bell (2007:5) emphasises that diversity has benefits for everyone in an organisation and suggests managers should implement a thorough managerial process that enables an environment that is suitable for all employees. The literature review findings suggest that researchers are in agreement that organisations benefit from a diversified staff with regard to the following aspects:

- appropriation of an ageing population

- legal compliance to recruit staff from under representative groups

- understanding and delivering service to a broader and multi-cultural customer base

- attracting new employees

- attracting new clients
- being able to choose from a larger recruitment pool

- becoming more attractive to potential stakeholders and business partners.

These are some of the benefits that come into play, but the following challenges also require consideration.

\section{Challenges of diversity}

Except for diversity's benefits, organisations may also face certain difficulties. Some of these challenges include issues, such as:

- employees feeling threatened by others who are different

- increased training costs

- claims of discrimination as well as reverse discrimination

- increased conflict

- increased absenteeism

- higher staff turnover.

Furthermore, Aghazadeh (2006:528) emphasises that if diversity management is not implemented correctly and reviewed regularly, it can lead to employee dissatisfaction and loss of productivity. With diversity encompassing so many different aspects of an individual (e.g., race, gender and age), the focus of this article is only on one aspect, namely age.

Organisations need to progressively leverage the multigenerational workforce values of interactive information societies. This implies an understanding of age diversity and of both the benefits and challenges. Organisations aware of generations understand how each of the four generational cohorts currently active in the workforce view 'work' and related issues, such as retirement and rewards. Leveraging generational awareness means focusing the organisation's attention on the 'shared values' of different generations. In terms of shared values, especially in interactive information societies, organisations should pay attention not only to each generation's values but also to the overlaps between different generations; this means an awareness of the so-called Cuspers that bridge generational boundaries with added benefit to interactive information societies. Whether organisations, such as AIS of HEI, are aware of their generational composition remains the question. This is consequently investigated in this article, beginning with an overview of the research method that was followed.

\section{RESEARCH METHODOLOGY}

The research methodology consists of a literature review to provide an overview of scholarship in generational awareness, co-worker relationships and diversity management, taking into account the various diversity aspects relevant to interactive information societies. These aspects were explored with the by an empirical research element mainly characterised by a quantitative design. The data collection instrument consisted of a questionnaire, which was piloted and scrutinised by the University of Johannesburg Statistics Consultation Service (StatCon) before it was distributed to selected higher education institutions in South Africa.

The research design combined Critical Theory and Generational Theory as part of its philosophical paradigm. The mixed-method research approach was followed; its nature was comparative with deductive and inductive conceptualisation and analysis of the research findings. The sequential exploratory design was decided upon as it studied the unknown relationships between different generations of a sample of academic information professionals. It then generalised the findings to the target population of academic information services in South Africa. The nonprobability sampling method of convenience sampling was used, adapted from DePoy and Gitlin (2005:148). The sample consisted of five South African HEIs. The survey excluded universities of technology and national research institutes. The participating HEIs were limited to those situated in and near 
Gauteng, namely the North West University, University of Johannesburg, University of South Africa (Unisa), University of the Witwatersrand and the University of Pretoria. The main criterion for participation was identified as the following: participants in the survey have to be full-time permanent or contract information professionals and this therefore excluded administrative staff and student assistants. This measure was taken to ensure that only qualified information professionals were surveyed.

The survey can be described as a self-administered, small-scale, cross-sectional, descriptive and quantitative survey, based on the individual information professional as the unit of analysis. 'Self-administered survey' indicates the manner in which the data was collected and indicates that the researcher did not meet with any of the respondents, individually or in a group. 'Smallscale' means that due to time and budget constraints, it was not possible to incorporate all the academic information services in South Africa into the sample and hence a sample was taken from Gauteng only. 'Cross-sectional' refers to the fact that the survey collected data from respondents at only one point in time. 'Descriptive' indicates the descriptive and exploratory nature of the survey as it does not attempt to discuss the causes of variables, but explores the relationship between them. 'Quantitative' means that the researcher tested the relationship between variables using numerical data. The individual information professional' as the unit of analysis indicates that the aim of the research is to investigate how information professionals of different ages contrast or agree with the different variables tested and to show how the individual differences are related across all the variables.

The survey focused on the different generations' attitudes regarding their view on work, work performance and co-worker relationships. A pilot study was conducted to test the validity and reliability of the questions and response. Based on the participants' suggestions and on the results of the pilot, some of the questions were adjusted. The online survey was then made available to 752 information professionals and a total of 145 valid responses were captured by StatCon which translates into a response rate of $(n) 19.28 \%$. A possible reason for the low response rate is that, except for the single reminder email that was sent to the participating HEI, no further reminder emails were sent out nearer to the survey's closure. Nonetheless, the survey rendered sufficient results and may be of even more value in further longitudinal studies aimed at investigating the age demography of academic information professionals in South Africa.

\section{FINDINGS AND ANALYSIS}

The research problem was directed at how diversity management influences the different generations of workers in terms of their work performance and co-worker relationships. Firstly, the four cohorts and the three intergenerational groups that typically constitute global and South African workforces are summarised in Figure 2.

Figure 2 aligns Traditionalists (T), Baby Boomers (BB), Generation $X(X)$, Generation $Y(Y)$ and the three Cusper groupings, $T$ / $\mathrm{BB}, \mathrm{BB} / \mathrm{X}$ and $\mathrm{X} / \mathrm{Y}$, to the birth date ranges (as listed earlier in Table 1). The Cusper birth date ranges are read as follows: 'the earliest year born into the Cusper group of other countries / earliest year born into the Cusper group in South Africa' to 'latest year born into the Cusper group of other countries / latest year born into the Cusper group in South Africa'. Seeing as the literature review findings provided no consensus regarding Cusper categorisation, their birth date ranges were determined by applying the principle of midrange plus or minus three years. For example, a South African Cusper X/Y is an individual born in or after the year 1986 and not later than the year 1993. Of significance is the gap that was identified regarding academic discourse aimed at Cuspers in the workforce.

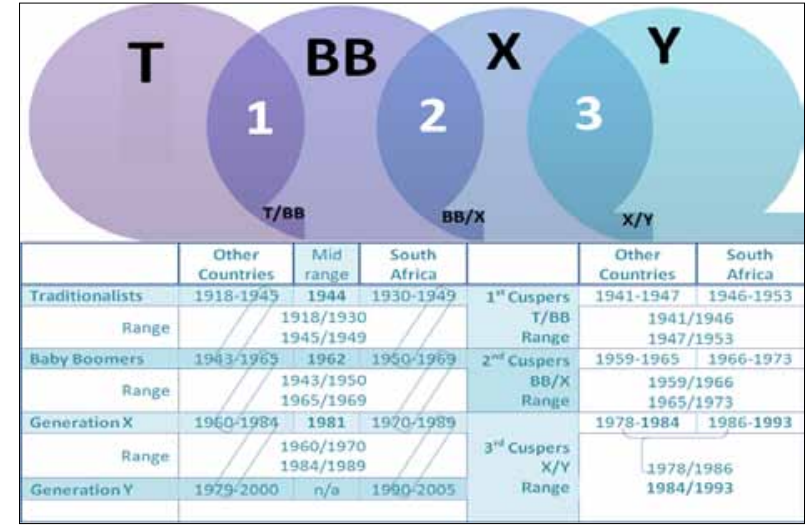

FIGURE 2

Cohorts currently active in the workforce
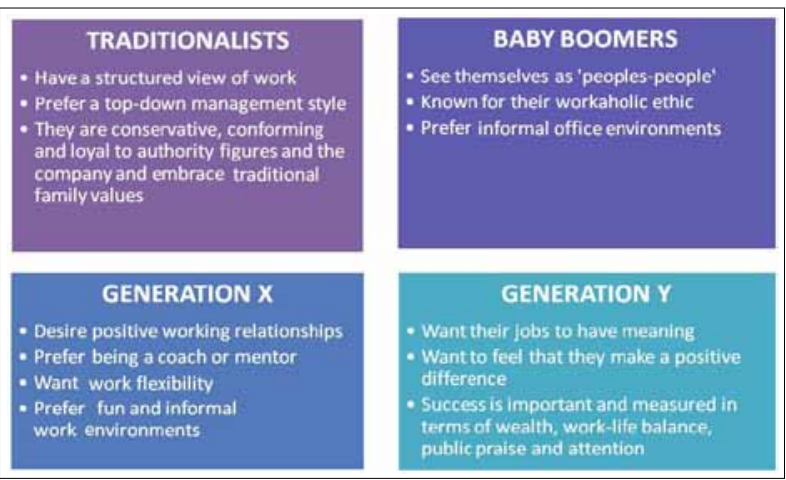

FIGURE 3

Work values of the different generations

Secondly, knowledge of each generation's work values is important as it helps to inform strategies to recruit and retain each cohort. Figure 3 summarises the findings on how each generation views work.

Thirdly, when looking at the type of rewards preferred by each generation, certain rewards appear to be valued across all generations, whilst others are shared only between some of the generations:

- Traditionalists and Baby Boomers see delayed retirement as a reward.

- Baby Boomers and Generation X value flexible retirement options and freedom.

- The Generation X and Generation Y cohort see a fun work environment, flexible work schedules and acquiring new skills as most rewarding.

Recognition and money are, notably, rewards valued by all four generations. Figure 4 illustrates the different cohorts' preferred rewards as well as the shared rewards. Of significance is that with the exception of money and recognition, Generation $\mathrm{Y}$ and Traditionalists do not value the same reward sentiments.

Whilst some generations value similar rewards, it is not implied by Figure 4 that a general need for, or an implied sense of freedom and flexible work schedules, are not also shared by all four the generations. Inversely, the literature review findings emphasised the need each generation has for a work-family life balance. It is clear that striving for a work-life balance is not unique to any one generation, instead it is a common desire; however, what constitutes this balance does differ. For the Traditionalists, balance can be achieved by offering retirement orientation courses to assist them with their transition into retirement. In the case of Baby Boomers, organisations can attempt to make clear the meaning of their work and the purpose of their lives. Generation X'ers will appreciate opportunities to divide their time appropriately between their work, family and fun in their struggle to balance their lives; whereas Generation 


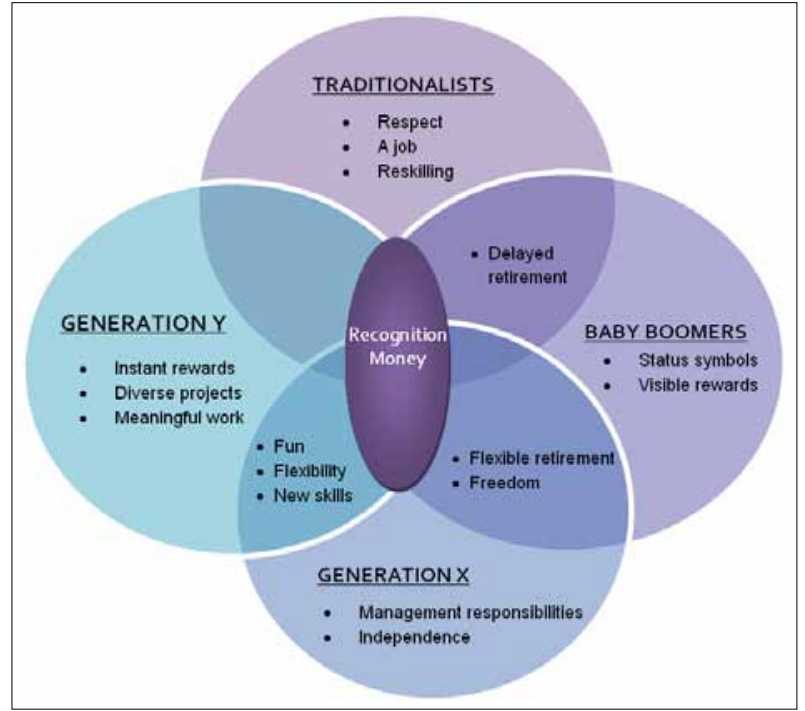

FIGURE 4

Most valued rewards of each generation

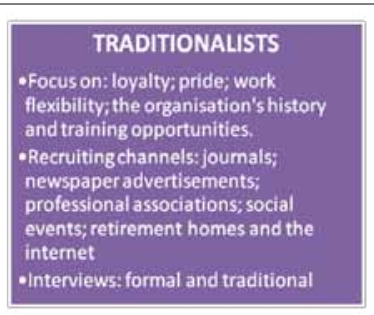

GENERATION $\mathrm{X}$

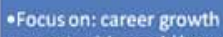
opportunities; paid leave; salary; fun working environment and work flexibility - Recruiting channels: multiplemedia such as magazines, newspapers anc the internet -Interviews: fast; less formal and more direct

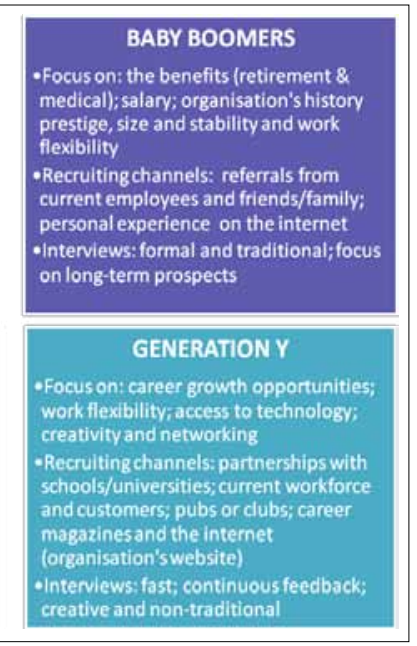

FIGURE 5

How to recruit the different generations

Y'ers will value flexibility in their work scheduling, dress codes and work programmes. Essentially, Generation Y, with their view that work and family cannot be divided, will appreciate a work environment which supports achieving work-life balance. Being conscious of each generation's preference in terms of attaining this balance can be a powerful message when organisations recruit employees.

Fourthly, to illustrate a targeted approach to recruiting different generations, the research findings are summarised in Figure 5, identifying those aspects to which organisations should pay attention to depending on the organisation's staffing needs.

From the above discussion, it seems clear that recruiting the different generations may require organisations today to employ different strategies than in the past. In order for these strategies to be successful, organisations must be aware of the career phases and life stages of each generation, as well as the message style and focus preferred by the different cohorts. Using the most appropriate advertising channel for each generation will also ensure that target recruiting will be successful, whilst it would be advisable for interviewers to take cognisance that each generation's views and expectations of interviews differ.

Fifthly, generations view retirement in a manner unique to their generational cohort. These retirement expectations are summarised in Figure 6.

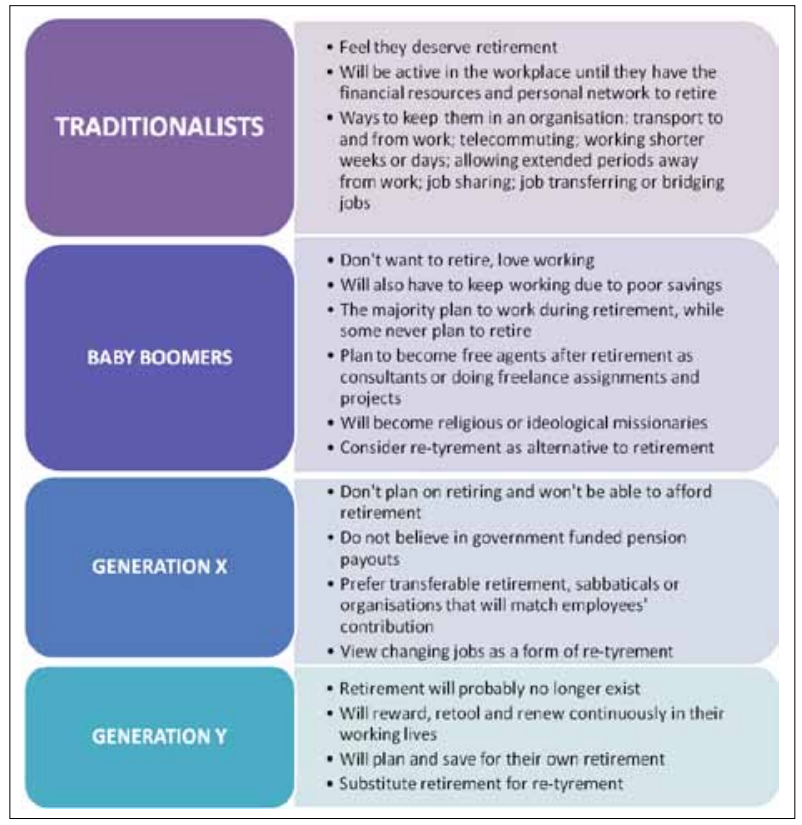

FIGURE 6

Retirement views of different generations

An interesting concept is that of 're-tyrement' instead of retirement, as preferred by Baby Boomers. According to Codrington and Grant-Marshall (2004:293) re-tyring is 'learning new working skills and planning how to make retirement work for them'.

From the preceding discussion it is clear that, although similarities between the four generations exist, each generation has a distinct and unique perception of work, which rewards motivate them, what their outlook on the balance between work and family life entails how they respond to recruitment and how their outlook on retirement differs. These differing perceptions influence the approach each of the generations will have in dealing with their co-workers. Acknowledging these differences could assist organisations in reducing workplace conflict and misunderstandings between co-workers.

To improve workplace cohesion, the literature review findings indicated that although all generations feel a need for 'belonging at work', each generation interprets 'belonging' differently. As the oldest working cohort, Traditionalists focus more on inclusion and harmony in teams, but will quickly disengage from work if they feel disrespected by younger co-workers. Baby Boomers prefer teamwork and group discussions, but they have an even greater preference for being the leaders of these teams and tend to exploit this leadership position for their own advancement. Raised to respect their elders in the workplace, the Baby Boomer cohort can feel affronted if they are challenged or treated as equals by the younger cohorts. Differing quite dramatically from their predecessors, Generation X'ers prefer to work on their own and if they have to work in teams they tend to favour teams that value individual contributions. Finally, Generation Y'ers, being the most team-orientated generation, feel comfortable working in teams but also require substantially more supervision than other cohorts. Involving Generation Y'ers and Baby Boomers in mentee-mentor teams or programmes could provide a workable solution for both parties, as Baby Boomers need to pass on their knowledge and expertise and a steep learning curve faces the youthful Generation Y'ers.

Having insight into a generation's perception of their sense of belonging, as reflected in their co-worker relationships, is extremely valuable to interactive information societies. This knowledge can be applied by organisations in formulating informed strategies for recruiting and retaining each cohort. Whilst certain values and rewards are shared across the different generations, others are shared only between two generations 


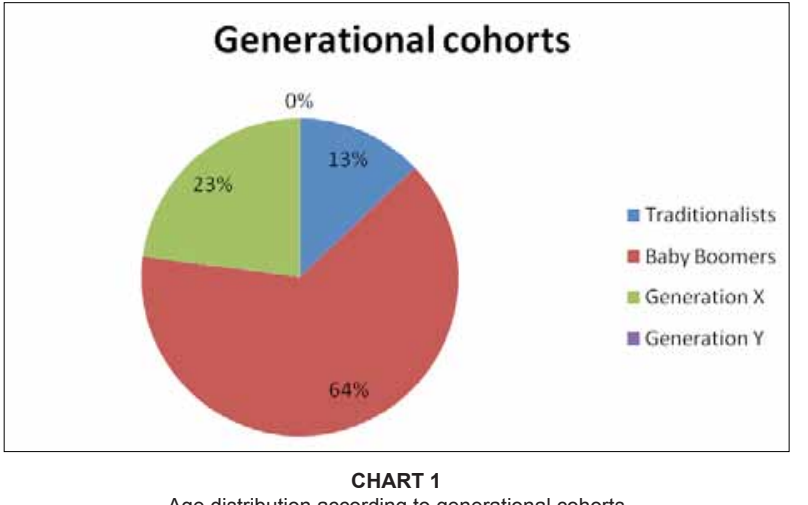

Age distribution according to generational cohorts

and organisations wishing to target not only one cohort will be well advised to focus their attention on the shared values. It is also clear that striving for a work-life balance is not unique to any one generation, instead it is the desire of all; however, what constitutes this balance does differ depending on the life stage and career phase of workers. Organisations should, however, take cognisance of the fact that employees are no longer willing to sacrifice their family life for their careers. Retirement options will have to become much more flexible and be presented to employees not only in monetary terms, but also as time off during their working lives.

From the preceding discussion it is observed that a potential source for intergenerational workplace conflict is the fact that each cohort has a different view of how they prefer to 'belong' at work. Except for Generation X, all the generations prefer team interaction, with the youngest generation treating all team members as equals regardless of age or experience. In the team environment this could lead to tension given that Traditionalists and Baby Boomers easily take offence if they are disrespected. Acknowledging the various generational cohorts can only assist organisations if they are aware of the generational composition of their organisations. Whether organisations such as HEI are aware of their generational composition remains questionable. The empirical research findings prove to be valuable in this regard. Chart 1 reflects the generational cohorts represented in the survey.

Chart 1 above shows that $64 \%$ of respondents are between the ages of 45 and 59 years, which indicates that the Baby Boomer cohort forms the majority. Of the respondents $23 \%$ are from Generation X, whilst Traditionalists account for $13 \%$ of the total respondents. As no respondents younger than 21 years of age participated in the survey, Generation Y did not form part of the statistical analysis. However, this finding does indicate the need for further research in terms of recruiting. Also, considering the large percentage of information professionals retiring in the next 10-15 years as portrayed in Chart 2, the research findings are a cause for concern.

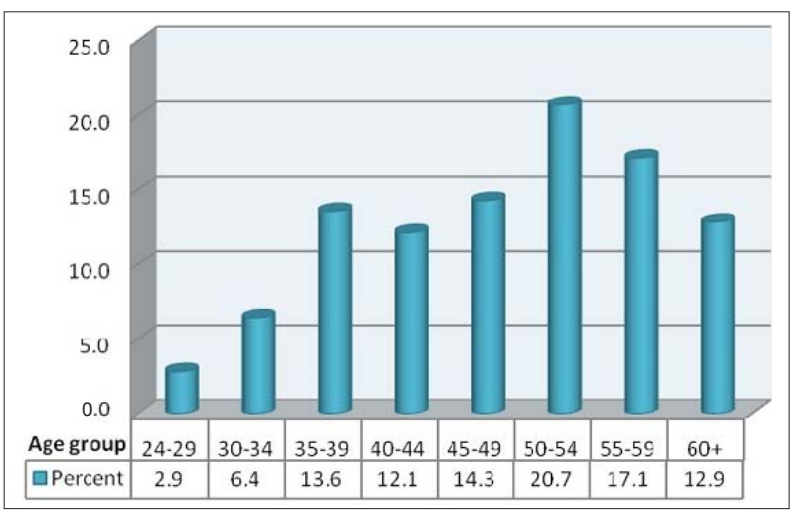

CHART 2

Age distribution of survey respondents according to StatsSA groupings
Finally, the most significant research findings are summarised as follows:

- Half of the South African academic information professionals will be retiring within the next 10-15 years and is more than four times the national average. This will result in an imminent staff exodus due to retirement and HEI need to establish planning and training for new middle and top management positions for succession planning.

- The high percentage of respondents retiring within the next 10-15 years confirms other research arguments related to Traditionalists and Baby Boomers. Because these two generations may find retirement an uneconomical option, they prefer to delay their retirement through various flexible options. Their preferred options include working shorter weeks or working from home.

- Despite Traditionalists being viewed as the most loyal generational cohort and the cohort preferring lifetime employment with a single employer, this study indicated that more Traditionalists had changed careers than any other cohort.

- The Baby Boomer respondents of this study did not attach a higher value to increased salaries than to spending time with their families.

- The study confirmed that both the Baby Boomer and Generation X cohorts place more value on cash bonuses and paid training courses or skills development than Traditionalists. Amongst the Baby Boomer and Generation $\mathrm{X}$ cohorts, Baby Boomers placed greater emphasis on paid training courses or skills development whilst the Generation $\mathrm{X}$ cohort placed greater significance on cash bonuses.

- The Generation X cohort showed the highest preference for being the leader in a team, disproving the notion that Baby Boomers most prefer to be leaders in a team.

These findings may possibly assist HEI in South Africa regarding the planning and training of new middle and top-management staff members which must form part of succession planning policies in order to avoid a leadership vacuum. In the conclusion to follow some suggestions with regard to generational awareness are made in order to establish a critical pathway to efficient co-worker relationships.

\section{CONCLUSION AND RECOMMENDATIONS}

This discussion suggests that an awareness of multi-generational workforce values can be of value in interactive information societies. To leverage generational awareness, based on the qualitative and quantitative findings of this study, two succinct recommendations are presented. Firstly, whilst different generations of co-workers showed similar preferences in terms of their work performance and co-worker relationships, it would be of great benefit for interactive information societies if more emphasis is placed on incorporating age diversity into diversity management and succession planning.

Secondly, organisations in general and HEI in particular are encouraged to recognise that successful recruitment, retention and succession policies cannot be developed or implemented if the preferences and values of the different generations are not taken into account. Policies that were effective earlier in recruiting and retaining Traditionalists and Baby Boomers will not necessarily resonate with Generation $X$ and Generation $Y$ employees. Research focusing particularly on attracting and retaining Generation Y employees to HEI should therefore be at the forefront.

\section{ACKNOWLEDGEMENT}

We wish to acknowledge the South African Library and Information (SALI) Trust for making a research grant available in support of the research conducted in fulfillment of the degree MPhil (Information Management) at the University of Johannesburg. 


\section{REFERENCES}

Aghazadeh, S-M, 2006, 'Managing workforce diversity as an essential resource for improving organizational performance', International Journal of Productivity and Performance Management, 53(5/6), 521-531.

Arnold, A.M., 2007, 'A situational analysis of national information policy, with special reference to South Africa', Doctoral thesis, University of Pretoria, South Africa.

Barnard, Z., 2008, 'Online community portals for enhanced alumni networking', Doctoral thesis, University of Johannesburg, South Africa.

Bell, M.P., 2007, Diversity in organizations, Thomson SouthWestern, Mason.

Bogaert, S. \& Vloeberghs, D., 2005, 'Differentiated and individualized personnel management: Diversity management in Belgium', European Management Journal 23(4), 483-493.

Boothby, R., 2006, The next wave of productivity tools: Web office, viewed 04 February 2008, from www.innovationcreators. com/Web\%20Office\%20White\%20Paper\%20-\%20Rod\%20 Boothby.pdf

Codrington, G. \& Grant-Marshall, S., 2004, Mind the gap, Penguin Group, London.

DePoy, E. \& Gitlin, L.N., 2005, Introduction to research: Understanding and applying multiple strategies, 3rd edn., Elsevier Mosby, Missouri.

Dombai, C. \& Verwey, S., 1999, 'The impact of organisational culture as a context of interpersonal meaning on the management of organisational diversity', Communicare, $18(2), 104-131$.

Dwyer, R.J., 2009, 'Prepare for the impact of the multigenerational workforce!', Transforming Government: People, Process and Policy, 3(2), 101-110.

Ferreira, A. \& Du Plessis, T., 2009, 'Effect of online social networking on employee productivity', South African Journal of Information Management, 11(1) viewed 11 June 2010, from www.sajim.co.za

Gursoy, D., Maier, T.A. \& Chi, C.G., 2007, ‘Generational differences: An examination of work values and generational gaps in the hospitality workforce', International Journal of Hospitality Management 27(3), 448-458.

Hallam, G. \& Lee, J., 2008, 'neXus: An Investigation Into The LIS Workforce In Australia', Australian Library and Information Association, viewed 22 September 2008, from www.alia. org.au/employment/workforce/NeXus\%20StageOne \%20 Australia\%20Final.pdf
Howe, N. \& Strauss, W., 2007, 'The next 20 years: How customer and workforce attitudes will evolve', Harvard Business Review 85(7/8), 41-52.

Human, L., 2005, Diversity management: For business success, Van Schaik, Pretoria.

Kagan, A., 2003, 'The transformation of South African librarianship: Survey results and analysis of current opinions', Progressive Librarian, 22,1.

Kennedy, M.M., 2002, 'Managing change: Understanding the demographics of the evolving workforce', Proceedings of the Annual Convention of the AAEP 2002, 48, 467-470.

Kreitz, P.A., 2008, 'Best practices for managing organizational diversity', The Journal of Academic Librarianship 34(2), 101-120.

Lancaster, L.C. \& Stillman, D., 2002, When generations collide: who they are. Why they class. How to solve the generational puzzle at work, HarperCollins, New York.

Mabokela, R.O. \& Mawila, K.F.N., 2004, 'The impact of race, gender and culture in South African higher education', Comparative Education Review 48(4), 369-416.

Mannheim, K., 1952, 'The problem of generations', Essays on the Sociology of Knowledge, pp. 276-320, Oxford University Press, New York.

Novkovic, S., 2007, 'R\&D, innovation and networking: Strategies for cooperative survival. Series: Advances in the Economic Analysis of Participatory \& Labor-Managed Firms, vol. 10', in T. Kato (ed.), Cooperative firms in global markets: Incidence, liability and economic performance, 205-232.

Sayers, R.M., 2006, 'Australia's changing workplace: a generational perspective', Doctoral thesis, Royal Melbourne Institute of Technology University, Melbourne.

Sayers, R.M., 2007, 'The right staff from X to Y: Generational change and professional development in future academic libraries', Library Management 28(8/9), 474-487.

StatsSA, 2007, Mid-year population estimates. Statistical release: P0302, Statistics South Africa, Pretoria.

Surowiecki, J., 2005, The wisdom of crowds: Why the many are smarter than the few, Little, Brown, London.

Van der Walt, S., 2010, 'Generational awareness in co-worker relationships in the interactive information society', M thesis, University of Johannesburg, South Africa.

Wilder, S., 1996, 'Generational Change and the niche for librarians', The Journal of Academic Librarianship 22(5), 385-386.

WSIS, 2005, World Summit on the Information Society: Outcomes, viewed 07 March 2010, from www.itu.int/wsis/outcome/ booklet.pdf 